\title{
Co-designing non-hierarchical community arts research: the collaborative stories spiral
}

Non-hierarchical community arts research

Paul Gilchrist University of Brighton, Brighton, UK

Claire Holmes and Amelia Lee LGBT Youth North West, Manchester, UK

Niamh Moore

University of Edinburgh, Edinburgh, UK, and

Neil Ravenscroft

University of Brighton, Brighton, UK
Received 2 June 2015 Revised 20 August 2015 Accepted 25 August 2015

\begin{abstract}
Purpose - The purpose of this paper is to examine the potential and durability of arts practice as research through developing a new approach to arts research that challenges the conventional association between dominant constructions of community and dominant modes of research.

Design/methodology/approach - A co-design approach, situated in arts practice, has been used to generate a conceptual framework that offers potential to open up the workings of communities by examining them from the standpoint of those who have everyday experience of these communities.

Findings - The paper argues that there can no longer be clearly demarcated boundaries between "academics" and "community partners" in a genuinely co-designed arts research process. Rather, there are "research partners" who share mutual recognition of skills and experiences that allow them to commit to a durable "new creative scholarship" that reflects their collective identities.

Social implications - The conceptual framework celebrates the life stories of individuals at the expense of the grand metanarratives favoured by empirical sociology and mainstream humanities. The framework reflects the commitment of the authors to create accounts of communities that do justice to their collective wisdom, dynamism and connectivity, as well as their transience, their needs to transform and their responses to change, in ways that reflect the lives of those involved rather than the needs of externally imposed disciplinary regimes.

Originality/value - The conceptual framework is a new approach to qualitative research; its value lies in putting the participants at the heart of the research process where they not only generate narrative, but also situate, mediate and remediate it in ways that extend conventional participative research practices.
\end{abstract}

Keywords Co-design, Arts practice, Community studies

Paper type Conceptual paper

(C) Authors. Published by Emerald Group Publishing Limited. This article is published under the Creative Commons Attribution (CC BY 3.0) licence. Anyone may reproduce, distribute, translate and create derivative works of this article (for both commercial \& non-commercial purposes), subject to full attribution to the original publication and authors. The full terms of this licence may be seen at http://creativecommons.org/licences/by/3.0/legalcode

The research upon which this paper is based was funded by the Arts and Humanities Research Council (AHRC), grant no. AH/K00669X/1: Networked Communities as Dynamic Co-Created Learning Environments. 
QRJ

15,4

\section{Introduction}

Conventional sociological approaches to researching community tend to presume that strong communities reflect stable and secure environments that act as "antidotes" or "refuges" to an ever-more fluid and dynamic social, cultural and globalised world (Cole and Goodchild, 2000; Crow, 2002a; Cerf, 2011; Hamalainen and Jones, 2011). Yet we do not "know", in any verifiable sense, that this is the case because little attention has been paid to how the "[...] the rich and messy domain [...]" of the human interactions that constitute community are constructed, represented and understood (Bruner, 1991, p. 4). This is largely because our understandings of "reality" have remained bound to established (scientific) hierarchical research methodologies (Polkinghorne, 1989), thus denying the possibilities offered by constructivist approaches to lived experiences (van Manen, 1997) that might help us understand what constitutes people's lives (Bruner, 2004).

In this paper, we seek to break the chains that have bound these dominant constructions of community to equally dominant modes of research, by building on Bruner's $(1991,2004)$ and, to a lesser extent, Polkinghorne's (1989) work on narrative inquiry. Our contribution is to offer a new co-designed conceptual framework that has the potential to open up the workings of communities by examining them from the narratives of those who have everyday experience of these communities. As such, we situate the framework within an arts practice approach to data generation that celebrates the narrative life stories of individuals as members of dynamic communities (Bruner, 1991, 2004; Miller, 2010; Wood and Brown, 2012; Namhila, 2014). In moving beyond current methods (Merrill and West, 2009; Elliot, 2009), the framework reflects our commitment to generate accounts of communities of people that do justice to their collective wisdom, dynamism and creativity, as well as their transience, their needs to transform, and their responses to change. The conceptual framework therefore seeks to generate knowledge about "us" as a collective, rather than "them" as a community, or "us \& them" as a reflexive but discipline-bound research project. In this context the "us" is recognition that there can no longer be clearly demarcated boundaries between "academics" and "community partners" in a sustainable co-designed research practice (see Petit et al., 2011). Rather, there are groups of people who share a mutual recognition of skills and experiences that allow them to commit to a "new narrative scholarship" through which they seek, through practice, to deepen their understandings of how their communities function.

Consistent with Savage and Burrows' (2007) critique of empirical sociology, we do recognise that attempts have already been made to move beyond conventional hierarchical approaches to research. We further recognise that these approaches have embraced new sources of data (see Thrift's, 2005, evocation of knowing capitalism) and new data generation techniques such as narrative inquiry (Bruner, 1991, 2004), phenomenology (van Manen, 1997; Laverty, 2003) and Participatory Action Research (PAR) (Charles, 2011; Durie et al., 2011; Durham Community Research Team, 2011). We also recognise a broader arts practice turn in community research, away from imposed constructs of causality towards the deeper descriptive narratives of those involved (Merrill and West, 2009; Elliot, 2009; Miller, 2010; Wood and Brown, 2012). While certainly offering more inclusive and interpretive versions of community research (Petit et al., 2011), we argue that space remains to address Bruner's (2004) concerns about the extent to which we have the capacity to understand what constitutes people's lives.

\section{The boundaries of current practice}

In their recent review of the meanings and conceptualisations of "community", Crow and Mah (2011) observe that the term continues to have positive connotations, despite several 
warnings to the contrary (Hoggett, 1997; Crow, 2002b). They also chart how annexation of the term has broadened its reach into many areas of civil and political society, whether under the title of "community" or according to some alternative conceptualisation, such as "social capital" (Putnam, 2000) or neighbourhood (Crow et al., 2002; Dorling and Thomas, 2004). Alongside these developments, Crow and Mah (2011) suggest that research into communities has similarly changed, from an underpinning in social scientific methods that have treated community members as research subjects, to artsbased action and participatory methods that have increasingly viewed community Non-hierarchical community arts research members as co-researchers (Reason and Bradbury, 2001; Root, 2007; Gilchrist, 2009). They further suggest that this is part of a broader trend towards "[...] the democratisation of the research process" (Crow and Mah, 2011, p. 4) that challenges conventional conceptions of authenticity, truth and the ownership of research outputs.

We situate this as part of a broader participatory turn; a complicated, ongoing practice which manifests differently in different domains. It seems obvious to us that to become engaged in the practice of participatory research is already to be entangled in a series of knots and chains of complicated histories and contemporary manifestations. This participatory turn certainly has parallels with PAR, particularly in terms of its deviation from a positivist notion of value-neutrality. However, we argue that the emphasis of participatory (arts based) research practice is less about PAR's professional and planned interventions to achieve socially and politically informed outcomes (Greenwood and Levin, 1998; Wynne-Jones et al., 2015), and more about new ways of thinking and being that allow participants to speak for themselves.

In addition, despite its growing popularity, the practice of participatory research continues to generate "[...] dissonance between the claims of theory and the reality of practice [especially] [...] around issues of power and control" (Charles, 2011, p. 364). While the contingencies of individual situations and practitioners contribute to this (Schön, 1983), recent arguments by Cerf (2011) and Wynne-Jones et al. (2015) suggest that the problem is both deeper and more intractable, because the relative power of the different actors is never neutral. This highlights the key methodological challenge of participatory research: that the actors (whether or not understood as co-researchers) arrive at the moment of research action from different places and with different agendas. They equally depart from the experience in different directions and with different intentions. While this may seem obvious and capable of being addressed, much current PAR seems unable (or unwilling) to accept that there is a "before and after" that is fully a part of the research(ed) environment.

While some commentators (e.g. Bertotti et al., 2011; Wynne-Jones et al., 2015) suggest that this is the result of disciplinary norms, we argue that it is more likely to stem from a failure to understand fully the nature of narrative as an expression of people's lives and experiences. It is here that we turn to Bruner's (1991, 2004) work. As Bruner (2004, p. 692) argues, following Ricoeur (1984), narratives must be understood as ways of accessing "lived time" through a process of accrual; that is, narratives do not exist, per se, but are constructed and reconstructed through the act of self-telling such that, eventually, people become the autobiographical narratives by which they tell about their lives (Bruner, 2004, p. 694). This element of structure, or form, is critical, because:

[...] life stories must mesh, so to speak, within a community of life stories; tellers and listeners must share some "deep structure" about the nature of a "life," for if the rules of life-telling are altogether arbitrary, tellers and listeners will surely be alienated by a failure to grasp what the other is saying (Bruner, 2004, p. 699). 
QRJ

15,4

As this suggests, the narrative form has to emerge from self-telling; it is thus a cognitive rather than an intellectual achievement, bound within the culture of the communities from whence the narratives have been generated. As Bruner (2004, p. 692) argues, narrative imitates life just as life imitates narrative. This means that "[...] the act of constructing a narrative $[\ldots]$ is considerably more than "selecting" events $[\ldots]$ and then placing them in an appropriate order. The events themselves need to be constituted in the light of the overall narrative" (Bruner, 1991, p. 8). This is very much in contrast to current understandings of PAR and associated approaches, which tend to give primacy to discrete events (Durose et al., 2011), with scant attention paid to the structural meshing of narratives described by Bruner (2004). This means that many aspects of narrative inquiry tend to be ignored, or at least downplayed, in both PAR and in conventional oral history research (Ritchie, 2003, 2012). These include questions about which stories are to be told, what happens once stories are remediated, whether by community members or later, by outsiders and how the iterative relationship between these processes of situating, generating and remediating stories can be understood and crucially performed. We seek to challenge this deficit, to bring the richness of Bruner's work into conversation with participatory approaches to data generation and analysis.

\section{Co-designing the collaborative stories spiral (CSS) as a conceptual framework for data generation}

The project team for the co-design work consisted of five people, two of whom nominally identified themselves as youth workers and three who identified themselves as academics. This group had worked together on a number of community projects and all had undertaken a range of academic, youth and community research and facilitation skills training. Through a series of co-created and facilitated workshops and training programmes, the team brought arts practice (via the ICA: UK's Technology of Participation (www.ica-uk.org.uk/facilitation-training/)) into conversation with more conventional participatory action approaches to research (see Kop et al, 2011; Pain et al, 2011) as a means of deepening understandings of the co-production of research. The team sought, through this process, to inhabit simultaneously the worlds of practice as research and research as practice in a process through which it could co-design its approach to community-based participatory research. Throughout the workshops, the team kept in mind ideas of working in a hermeneutic circle of the type described Laverty (2003), with reference to the work of Heidegger (1962) and Kvale (1996):

[...] all understanding is connected to a given set of forestructures, including one's historicality, that cannot be eliminated. One, therefore, needs to become as aware as possible and account for these interpretive influences. This interpretive process is achieved through a hermeneutic circle which moves from the parts of experience, to the whole of experience and back and forth again and again to increase the depth of engagement with and the understanding of texts [...]. Kvale [...] viewed the end of this spiralling through a hermeneutic circle as occurring when one has reached a place of sensible meaning, free of inner contradictions, for the moment (Laverty, 2003, p. 9).

The outcome of the process is a co-designed multi-method conceptual framework for organising the generation of data about personal and community narratives. This framework, termed the CSS - inspired by Laverty's evocation of spiralling through a hermeneutic circle - represents a "shared space" that has cohered through the co-design 
process (see Figure 1). The framework - which is reminiscent of Kop et al's (2011) pedagogic model of the individual learning environment - has developed through several iterations, informed by arts practice, youth facilitation techniques and by sociological, geographical, pedagogic and historical approaches to the generation of community Non-hierarchical community arts research stories, as well as recognition of surprising overlaps between these approaches. We suggest that it is an example of Star's "boundary object", that is "[...] at once material and processual [...] [and] resides between social worlds (or communities of practice) where it is ill structured" (Star, 2010, pp. 604-605).

By conceptualising the CSS as a "boundary object", our concept allows for flexible structures that offer a non-hierarchical approach to arts research practice that does not involve (so much) academic mediation. Informed by Bruner's conceptualisation of narrative inquiry and Laverty's hermeneutic spiral, the CSS facilitates the creation of a multi-layered narrative practice/project in which we seek to establish a transformed, non-hierarchical, way of doing and communicating participatory research. Our practiceand framework - seeks to guide communities through a recursive spiral process that moves between the whole and parts of experience, as a means of establishing a shared structure about the nature of life (Bruner, 2004). Although the hermeneutic circle could have infinite depth and complexity, at this early stage in the development of the CSS we have limited it to four key stages in the self-telling of a narrative, identified as situating stories, generating stories, mediating stories and remediating stories.

The first stage, "situating stories", concerns the spatial and temporal contexts of the individuals, groups and networks under study, as well as key social and organisational properties that have informed and shaped the histories of the individuals, groups and networks. This phase corresponds to a process of "salvage work" (Hall, 1988, p. 73) to excavate the contingent relations of historical context, reconstructing practices, communities and institutions which affect meaning and through which stories are experienced and become understandable. As Bruner (1991) observes, narrative is much more than the ordering of events, and requires situating. But this goes further, because the accrual of narratives builds towards - constructs - the culture from which the stories are situated, meaning that the situating of the stories both constitutes and is constituted by the community narrative itself.

Once the stories have been situated, the next stage is about generating stories, or narratives. This is the social and participatory research phase, influenced by stories and narratives that can be produced at the individual and/or community level. It includes a focus on the critical incidents which are constructed - or coalesce - as prominent memories in the lives of communities, groups and individuals. It also relates to the documents that play a role in capturing, narrating and sustaining significant and shared moments which are generative of further connections between various actors. We acknowledge here that undertaking this phase requires sensitivity to the power of archivists, the cataloguing of documents and the legal governance of public/private documents and what is recorded in private. Following Derrida (1998) and Steedman (2002), we further recognise that this has serious impacts on what it is possible to tell.

The next phase, "mediating stories" is a reflexive phase where a narrative or story begins to be told within a community and is received by a reader or audience, but the story is necessarily incomplete and unsettled - as is the way with autobiography (Bruner, 2004). There is an element of hermeneutic jostling over the meanings of stories, leading (possibly) to some consensual revisions being made, or different versions being told. Here, the community may dispute the ordering and organisation of events of the past into a "followable" story and agitate for revisions to the shape of the story, its selection of key 


$$
\begin{aligned}
& \text { QRJ } \\
& 15,4
\end{aligned}
$$

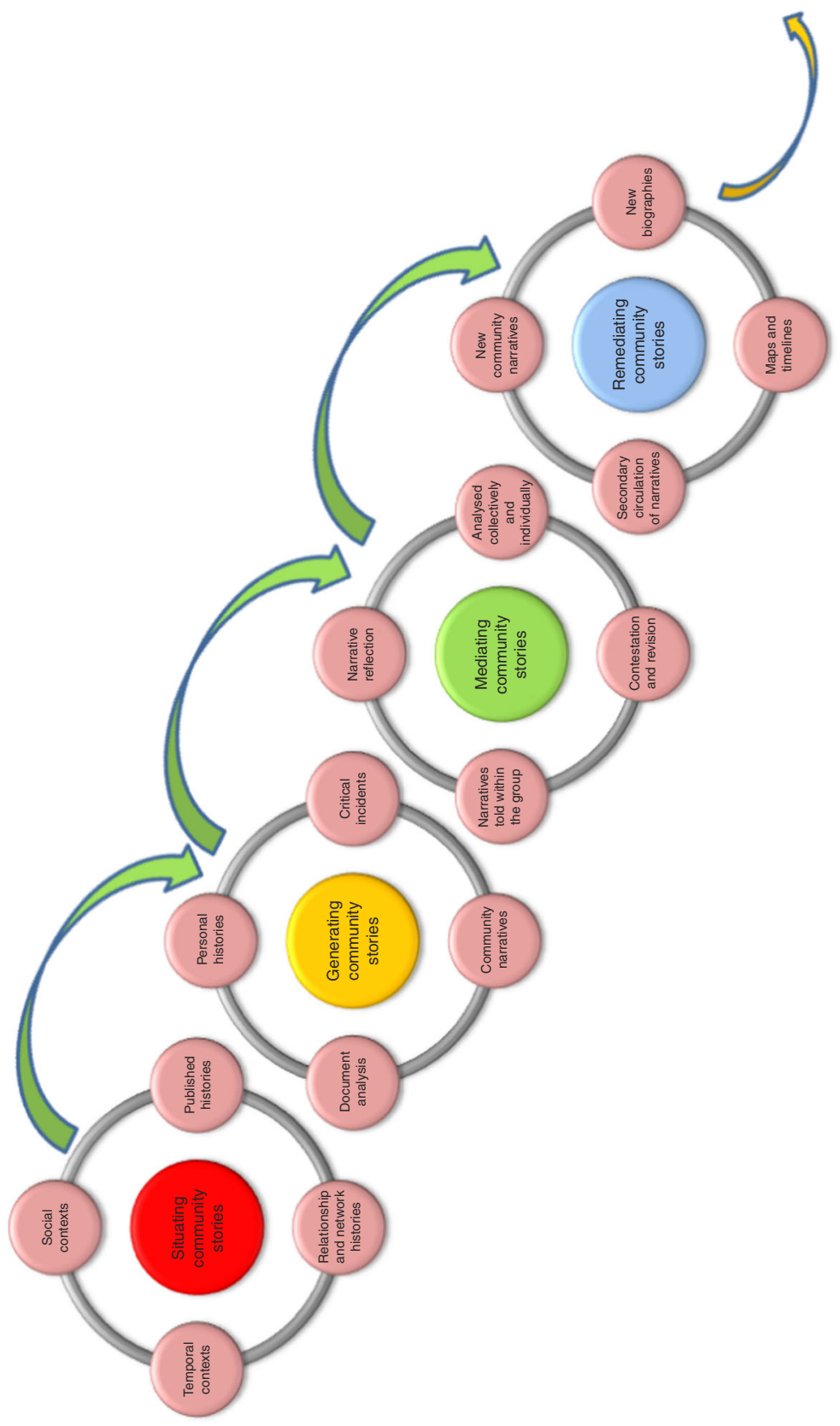

Figure 1.

The collaborative stories spiral 
events and narrative arc. However, as Bruner (2004) observes, there needs to be shared (situated) structure within which these negotiations take place, or some members of the community are likely to be alienated as their voices and stories become marginalised.

Finally, the "remediating stories" stage, is where a reasonably settled narrative is

produced for wider consumption. This phase therefore concerns the production of new (auto)biographic and historic materials; it is during this phase that the model is realised as a creative tool for expressing distinct and recognisable narratives and histories about communities, their participants and ongoing networks and relationships. Further communication, collaboration and exchange may occur as a result of remediating community stories through various representational outlets and social networks - hence, the inclusion of an arrow that signals new futures and horizons. A further - and opposite - pathway is also present, to illustrate the many dimensions in which the model can be used. Thus, in common with PAR approaches, individual studies can commence with the contexts of community stories (situating to remediating), but there is also a pathway that can start at the "generating community stories" phase, which illustrates that the case study can proceed with personal histories, critical incidents and document analysis or community narratives in order to generate insights into contexts and futures.

\section{Discussion and conclusions: the mutability and mobility of the CSS}

At the start of this paper we declared that we wanted to "break the chains that have bound dominant constructions of community to equally dominant modes of research". We feel that, through the use of an arts practice approach to research, the CSS offers the possibility of achieving this. At its simplest, the CSS creates a space where narratives can be situated, constructed, mediated and remediated, building on what Bruner (1991, 2004) has described as a process of cognitive accrual. Star's (2010, p. 602) concept of a "boundary object" has been useful for articulating this project. For Star, a boundary object is not so much an edge or border, but rather a "shared space" that coheres through a collaborative effort involving sharing and transfer of knowledge and skills. Boundary objects are structures for doing things together which, like road maps, may point in directions and lead to different ends, involving interpretative flexibility which gives scope for individuals to determine directions based upon use and interpretation:

The object (remember to read this as a set of work arrangements that are at once material and processual) resides between social worlds (or communities of practice) where it is ill structured. When necessary, the object is worked on by local groups who maintain its vaguer identity as a common object, while making it more specific, more tailored to local use within a social world, and therefore useful for work that is NOT interdisciplinary. Groups that are cooperating without consensus tack back-and-forth between both forms of the object (Star, 2010, pp. 604-605).

Following Bruner (2004), a boundary object thus allows non-hierarchical collaboration without the need for consensus about content (which tends to vary over time), as long as there is consistent (narrative) form. Boundary objects thus carry a notion of mutability and recognise that in practice methods can move, be displaced and adapt. This is important because it reveals some practicalities associated with multi-method construction between university and community partners: that if a process is to be sustainable, a shared space such as the CSS requires a process of co-contribution to set the boundaries of work and also the process of "letting go" - a course of action that facilitates further co-operation even if absolute consensus is not achieved. This is very 
QRJ

15,4 much redolent of the completion of Laverty's $(2003$, p. 9) hermeneutic circles, when practice "[...] has reached a place of sensible meaning, free of inner contradictions, for the moment".

There are important lessons here about how methods work in practice. By acknowledging variance and fluidity we become less concerned with hierarchies, standardisation and replicability and with the need to impose rigidities on the form of practice. Neither should we be precious about this when those that use it make their own adaptations and alterations. Indeed, this should please us:

Fluid spatiality suggests that varying configurations, rather than representing breakdown and failure, may also help to strengthen objects (Law and Mol, 2001, p. 615).

So, in reflecting on the conceptualisation of the CSS, we are free to reject two tenets of (positivist) scientific epistemology: standardisation and control. These are important because we are not set on keeping the conceptual framework stable. Rather, our role is, through sensitive non-hierarchical practice, to release control of the process so that the boundary can be shaped and formed, but within limits that respect the community's wants and needs. Temporal dimensions are important here too. The attention given to the stages of PAR conceived by the CSS allows for further places of engagement and creative activity. The practice of making involves a commitment to being with others and a process of sharing and interacting that can encourage people to start telling their stories and making sense of the everyday experiences, events and people that have composed their communities over time (Gauntlett, 2011). A qualitative research endeavour with both collaborating and making at its heart needs to give attentive consideration to the ways in which we participate and the social relations that are necessary for us to be able to contribute to the research. Thus whilst the boundary object creates an arrangement for doing things together, the process requires time for assembly, trust-building, contemplation, remembrance (and even argument and dispute), alongside other forms of emotional and embodied engagement. These social foundations for dialogue are necessary not only as part of the epistemological frame and methodological process but also in meeting ethical demands to equip participants with the confidence to speak, willingness to share and the sense that they are being listened to (Hawkins, 2011).

To this extent our role as researchers is akin to that of the shepherd, allowing communities the space and time to explore and nourish themselves while retaining the facility (or ability) to guide those communities in ways that ensure that the boundaries of the object (the method) reside in those communities. The CSS is nothing without the communities that it will serve. So, it has to be intelligible to these communities, to look attractive, to be capable of gathering people and focusing attention and of recruiting some community members to take care of it. The method has (some of) its origins in a process co-design between academics and community partners, but moves beyond the meeting room to the community itself. It thus embodies both practice as research and research as practice; it is nothing without both.

Does the rejection of (linear and hierarchical) standardisation mean that we reject empiricist realism? If we are to trace the dynamism of communities we surely need to construct and calibrate a tool which can accurately relay what is understood to be the real world and its real attributes. To some extent we are harbouring in this as empiricist methodological inheritance - because when we started we wanted to know something about the people and communities with whom we were working. The data can be usefully published to generate knowledge about a version of social reality - the 
connections and flows of people as they move through different communities. However, the framework, which leans towards narrative, suggests that absolute knowledge of the social world is not possible, although individual perspectives can be generated and the researcher (or wider community as analysts) can construct credible common narratives Non-hierarchical community arts research around particular points and moments. The multi-methods enable a form of triangulation, not in terms of a quest for validity but in terms of voicing multiple perspectives that allow us to view complexity "[...] to map out, or explain more fully, the richness and complexity of human behaviour by studying it from more than one standpoint" (Cohen and Manion, 1980, p. 269).

Yet, Star insists that the construction of a boundary object requires methodological standardisation, or at least "a degree of stability about what particular objects connote" (Bowker and Star, 1999, p 16; Star and Griesemer, 1989, pp. 393-410). As Laverty (2003) has observed, the tacking-back-and-forth (or spiralling) of a boundary object between participants involves at least a temporary commitment to maintain the form of the object, to try to control it and seek equivalence (Star, 2010, p. 613). Bruner (1991, pp. 4-5) does not dispute this need for form, even while arguing that the acceptability of the version of reality found in narrative inquiry "[...] is governed by convention and "narrative necessity" rather than by empirical verification and logical requiredness [...]". At the core of the $\mathrm{CSS}$, therefore, is a generic set of principles for the research which form the shared space of the boundary object: histories, narratives, events and incidents elicited through a process of situation, generation, mediation and remediation. Beyond this set of principles might be dominant and residual elements, ways through the framework and pathways which emerge from its use and which are informed by local practice and practitioners/researchers. This is the "shared deep structure" that Bruner (2004, p. 699) argues must be present for communities of life stories to "mesh". So, we anticipate the model to be dynamic, to be adopted or resisted, to guide and be guided, as common methodological purposes (or values?) are played out. In these boundary ways we believe that the CSS adds a new sustainable and non-hierarchical dimension to co-produced narrative participatory research.

In concluding, the key point that we wish to emphasise is that a process of co-design creates a shared space through which co-operation can emerge. The conceptual framework becomes productive in helping us construct social worlds that are implicated in an "ontological politics" about what is, or could be, made more real through the research. Thus, whilst we have participated in coalescing a multi-method framework, we anticipate that it will move, allowing us to deepen and widen our own involvement with individual and connected communities. As Green (2010) has observed in another context, the status of the boundary object can be ascribed to participation. An effect of standardisation and the centrality of methods shared across collaborating epistemic communities is to bring disparate institutions and individuals together (although Green also observes how routinised and tightly controlled facilitation emblematic of the PAR approach - can equally close down participation). The reflections we need to develop further, then, are about co-design and participation in the contexts of our choices about researching communities and our political commitments to the communities whom we research. Posed as a research question we might ask: "does co-designed research - using the Collaborative Stories Spiral - perform community connection in a way that facilitates an alternate arts practice research"? Or, put in another way: "can an alternate arts research practice be brought into being through the Collaborative Stories Spiral"? 
QRJ

15,4

While these questions are clearly for the future, we conclude by reflecting on where we started: the possibilities of offering a new methodological approach to undertaking sociological research. It is certainly clear to us that where, once, sociological research offered something new - sample surveys offering causal explanations of social phenomena, for example - it no longer does, certainly in isolation. Following Savage and Burrows (2007), it may well even be irrelevant to contemporary society. Yet, as we have suggested, this is not the end of/for sociological approaches to research, but rather an invitation to develop new artsbased relationships and modes of working between different types of researchers (in our case academic and community researchers). The CSS is an evocation of this new relationship, co-designed around co-situated, generated and mediated stories that offer deep insights into the relationships between individuals and the communities to which they belong. This is no longer part of a "professional" and analytical process of generating data to answer specific questions, but rather a means of illuminating and capturing complex and often opaque meanings and understandings of the "wholeness" (Miller, 2010, p. 2) of people's lives.

Rather than seeking a singular temporally constrained answer, therefore, the CSS reminds us of the contingency and dynamism of people's lives and the stories that they tell and retell about their lives. For us, therefore, the CSS does offer the possibility of an alternate participatory socio-arts research practice - one that is messy, dynamic, contingent and as alive as those with whom it seeks to engage. While challenging the remote hierarchical professionalism, order and power of empirical (sociological) research, this new research practice offers something far more valuable: data generated by and for ordinary people that allow unlimited access into individual and shared worlds in times, spaces and ways that until now have been unimaginable.

\section{References}

Bertotti, M., Jamal, F. and Harden, A. (2011), "A review of conceptualisations and meanings of 'community' within and across research traditions: a meta-narrative approach", Scoping study report to AHRC Connected Communities Programme, Swindon, available at: www. ahrc.ac.uk/FundingOpportunities/Pages/connectedcommunities.aspx (accessed 11 February 2013).

Bowker, G. and Star, S. (1999), Sorting Things Out, Classification and its Consequences, MIT Press, Cambridge, MA.

Bruner, J. (1991), “The narrative construction of reality”, Critical Inquiry, Vol. 18 No. 1, pp. 1-21.

Bruner, J. (2004), "Life as narrative”, Social Research, Vol. 71 No. 3, pp. 691-710.

Cerf, M. (2011), "Is participatory research a scientific practice?”, Journal of Rural Studies, Vol. 27 No. 4, pp. 414-418.

Charles, L. (2011), “Animating community supported agriculture in North East England: striving for a 'caring practice”, Journal of Rural Studies, Vol. 27 No. 4, pp. 362-371.

Cohen, L. and Manion, L. (1980), Research Methods in Education, 3rd ed., Routledge, London.

Cole, I. and Goodchild, B. (2000), "Social mix and the 'balanced community' in British housing policy - a tale of two epochs", Geojournal, Vol. 51 No. 4, pp. 351-360.

Crow, G. (2002a), Social Solidarities: Theories, Identities and Social Change, Open University Press, Buckingham. 
Crow, G. (2002b), “Community studies: fifty years of theorization”, Sociological Research Online, Vol. 7 No. 3, 14pp, available at: www.socresonline.org.uk/7/3/crow.html (accessed 18 September 2013).

Crow, G. and Mah, A. (2011), "Conceptualisations and meanings of 'community': the theory and operationalization of a contested concept", Scoping study report to AHRC Connected Communities Programme, Swindon, available at: www.ahrc.ac.uk/FundingOpportunities/ Pages/connectedcommunities.aspx (accessed 11 February 2013).

Non-hierarchical community arts research

Crow, G., Allan, G. and Summers, M. (2002), "Neither busybodies nor bodies: managing proximity and distance in neighbourly relations", Sociology, Vol. 36 No. 1, pp. 127-145.

Derrida, J. (1998), Archive Fever: A Freudian Impression, University of Chicago Press, Chicago, IL.

Dorling, D. and Thomas, B. (2004), People and Places: A 2001 Census Atlas of the UK, Policy Press, Bristol.

Durham Community Research Team (2011), "Community-based participatory research: ethical challenges", Scoping study report to AHRC Connected Communities Programme, Swindon, available at: www.ahrc.ac.uk/FundingOpportunities/Pages/connectedcommunities.aspx (accessed 11 February 2013).

Durie, R., Lundy, C. and Wyatt, K. (2011), "Researching with communities: towards a leading edge theory and practice for community engagement", Scoping study report to AHRC Connected Communities Programme, Swindon, available at: www.ahrc.ac.uk/FundingOpportunities/ Pages/connectedcommunities.aspx (accessed 11 February 2013).

Durose, C., Beebeejaun, Y., Rees, J., Richardson, J. and Richardson, L. (2011), "Towards co-production in research with communities", Scoping study report to AHRC Connected Communities Programme, Swindon, available at: www.ahrc.ac.uk/FundingOpportunities/ Pages/connectedcommunities.aspx (accessed 11 February 2013).

Elliot, J. (2009), Using Narrative in Social Research: Qualitative and Quantitative Approaches, Sage, London.

Gauntlett, D. (2011), Making is Connecting, Polity, Cambridge.

Gilchrist, A. (2009), The Well-Connected Community: A Networking Approach to Community Development, 2nd ed., Policy Press, Bristol.

Green, M. (2010), "Making development agents: participation as boundary object in international development", Journal of Development Studies, Vol. 46 No. 7, pp. 1240-1263.

Greenwood, D.J. and Levin, M. (1998), Introduction to Action Research, Sage Publications, Thousand Oaks, CA.

Hall, S. (1988), "The toad in the garden: thatcherism among the theorists", in Nelson, C. and Grossberg, L. (Eds), Marxism and the Interpretation of Culture, Macmillian, Basingstoke, pp. 35-73.

Hamalainen, L. and Jones, K. (2011), "Conceptualising community as a social fix: argument and persuasion in health, housing and local governance", Scoping study report to AHRC Connected Communities Programme, Swindon, available at: www.ahrc.ac.uk/Funding Opportunities/Pages/connectedcommunities.aspx (accessed 11 February 2013).

Hawkins, H. (2011), "Dialogues and doings: sketching the relationships between geography and art”, Geography Compass, Vol. 5 No. 7, pp. 464-478.

Heidegger, M. (1962), Being and Time, Harper, New York, NY.

Hoggett, P. (Ed.) (1997), Contested Communities: Experiences, Struggles, Policies, Policy Press, Bristol.

Kop, R., Fournier, H. and Mak, J.S.F. (2011), “A pedagogy of abundance or a pedagogy to support human beings? Participant support on massive open on-line courses", The International Review of Research on Open and Distance Learning, Vol. 12 No. 7, pp. 75-93. 
QRJ

15,4

Kvale, S. (1996), InterViews: An Introduction to Qualitative Research, Sage, Thousand Oaks, CA.

Laverty, S.M. (2003), "Hermeneutic phenomenology and phenomenology: a comparison of historical and methodological considerations", International Journal of Qualitative Methods, Vol. 2 No. 3, Article 3, available at: www.ualberta.ca/ iiqm/backissues/ 2_3final/pdf/laverty.pdf (accessed 14 August 2015).

Law, J. and Mol, A. (2001), "Situating technoscience: an inquiry into spatialities", Environment and Planning D: Society and Space, Vol. 19 No. 5, pp. 609-621.

Merrill, B. and West, L. (2009), Using Biographical Methods in Social Research, Sage, London.

Miller, S. (2010), "Understanding impact in social and personal context: making a case for life stories in volunteering research", paper presented at the NCVO/VSSN Researching the Voluntary Sector Conference, Leeds University, Leeds, 6 September, available at: http://pathwaysthroughparticipation.org.uk/wp-content/uploads/sites/3/2010/ 09/Understanding-impact-in-social-and-personal-context_paper3.pdf

Namhila, E.D. (2014), "Uncovering hidden historical narratives of village women in Namibia", Qualitative Research Journal, Vol. 14 No. 3, pp. 243-258.

Pain, R., Whitman, G. and Milledge, D. and Lune Rivers Trust (2011), Participatory Action Research Toolkit: An Introduction to Using PAR as an Approach to Learning, Research and Action, Department of Geography, University of Durham, Durham.

Petit, S., Mougenot, C. and Fleury, P. (2011), "Stories on research, research on stories", Journal of Rural Studies, Vol. 27 No. 4, pp. 394-402.

Polkinghorne, D.E. (1989), "Phenomenological research methods", in Valle, R.S. and Halling, S. (Eds), Existential-Phenemenological Perspectives in Psychology, Plenum, New York, NY, pp. 41-60.

Putnam, R.D. (2000), Bowling Alone: The Collapse and Revival of American Community, Simon \& Schuster, New York, NY.

Reason, P. and Bradbury, H. (2001), "Introduction: inquiry and participation in search of a world worthy of human inspiration", in Reason, P. and Bradbury, H. (Eds), Handbook of ActionResearch, Sage, London, pp. 1-13.

Ritchie, D.A. (2003), Doing Oral History, Oxford University Press, Oxford.

Ritchie, D.A. (Ed.) (2012), Oxford Handbook of Oral History, reprinted ed., Oxford University Press, Oxford.

Ricoeur, P. (1984), Time and Narrative, Volume 1, Trans by McLaughlin, K. and Pellaeur, D., University of Chicago Press, Chicago, IL.

Root, M. (2007), "Community-based research", in Outhwaite, W. and Turner, S. (Eds), The Sage Handbook of Social Science Methodology, Sage, London, pp. 565-577.

Savage, M. and Burrows, R. (2007), "The coming crisis of empirical sociology”, Sociology, Vol. 41 No. 5, pp. 885-899.

Schön, D.A. (1983), The Reflective Practitioner: How Professionals Think in Action, Ashgate, Aldershot.

Star, S.L. (2010), "This is not a boundary object: reflections on the origin of a concept", Science, Technology \& Human Values, Vol. 35 No. 5, pp. 601-617.

Star, S.L. and Griesemer, J. (1989), “Institutional ecology, 'translations' and boundary objects: amateurs and professionals in Berkeley's Museum of Vertebrate Zoology, 1907-1939”, Social Studies of Science, Vol. 19 No. 3, pp. 387-420.

Steedman, C. (2002), Dust: The Archive and Cultural History, Rutgers University Press, New Brunswick, NJ.

Thrift, N. (2005), Knowing Capitalism, Sage, London. 
van Manen, M. (1997), Researching Lived Experience: Human Science for an Action Sensitive Pedagogy, 2nd ed., The Althouse Press, London.

Wood, M. and Brown, S. (2012), "Film-based creative arts enquiry: qualitative researchers as auteurs", Qualitative Research Journal, Vol. 12 No. 1, pp. 130-147.

Wynne-Jones, S., North, P. and Routledge, P. (2015), "Practising participatory geographies: potentials, problems and politics", Area 2015, Vol. 47 No. 3, pp. 218-221. doi: 10.1111/ area.12186.

\section{Corresponding author}

Professor Neil Ravenscroft can be contacted at: N.Ravenscroft@brighton.ac.uk 